Maha T Al-Saffar BDS, MSc (Lec)

\section{Efficacy of Paracetamol versus Celebrex on the Control of Post Operative Complications of Lower Third Molars}

\author{
Department of Dental Basic Sciences
}

College of Dentistry, University of Mosul

$$
\begin{aligned}
& \text { الحلاصة } \\
& \text { الأهداف: تحدف الدراسة إلى مقارنة تأثير عقار السليبر كس بيرعة } 400 \text { ملغم يوميا وعن طريق الفم مع تأثير عقار البراسيتامول ويرعة } 1000
\end{aligned}
$$

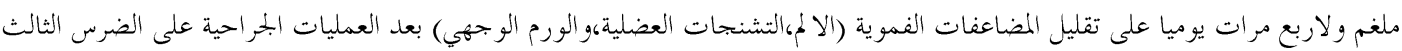

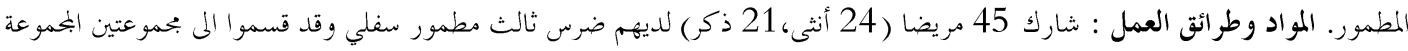

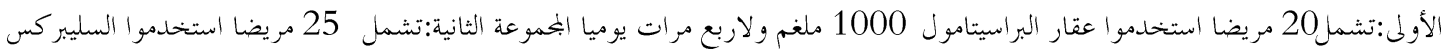

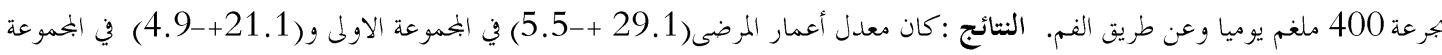

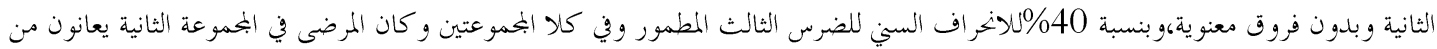

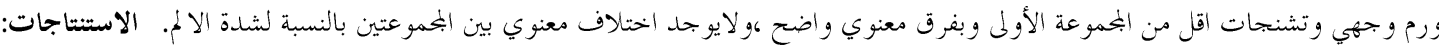

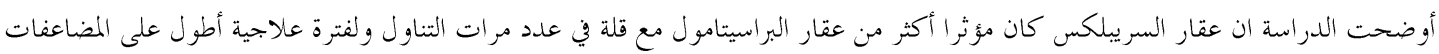

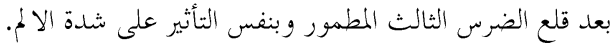

Aims: To compare the efficacy of celebrex $400 \mathrm{mg}$ orally one time daily with paracatamol $1000 \mathrm{mg}$ orally four times daily on reducing post operative oral complication (facial swelling, trismus and pain) after third molar surgery. Materials and Methods: A total of 45 patients (24 females, 21 males) with impacted lower third molars divided into two groups; Group I: Twenty patients treated with paracetamol $1000 \mathrm{mg}$ orally four times daily. Group II: Twenty five patients treated with celebrex $400 \mathrm{mg}$ orally one time daily. Results: The mean age of patients was $(29.17 \pm 5.0)$ in group I and $(27.1 \pm 4.9)$ in group II with no significant differences, with a higher percentage of mesioangular impaction $40 \%$ among other type of impaction in two groups. Patients in group II suffer from less facial swelling and trismus with a significant differences $p \leq 0.05$ compared with group I, but the two groups showed no significant differences in related to pain $(p>0.05)$ after third molar's surgical removal. Conclusions: Celebrex is more effective than paracetamol with less frequency of administration and longer duration of action in reducing post operative oral complication (swelling and trismus), but with some analgesic effect after surgical removal of lower third molars.

Key words: Celecoxib anti - inflammatory effect, analgesic in dentistry, post - operative oral complication of lower third molar surgery

Al-Saffar MT. Efficacy of Paracetamol versus Celebrex on the Control of Post Operative Complications of Lower Third Molars. Al-Rafidain Dent J. 2011; 11(1):24-31.

Received: $10 / 5 / 2009 \quad$ Sent to Referees: $17 / 5 / 2009$

Accepted for Publication: 16/6/2009

\section{INTRODUCTION}

Third molar's surgical extraction is a traumatic procedure and the most common in the oral and maxillofacial field. ${ }^{(1,2)}$ Being a highly vascularized area, predominantly constituted by loose connective tissue, a series of functional and structural alteration is expected, among them, the liberation of exudates and subsequent swelling, trismus and pain. To control post operative inflammation and symptom associated, it is neces- sary to provide an adequate anti - inflammatory and analgesic therapy. ${ }^{(3)}$

Acetaminophen (paracetamol) is acetic acid and $\mathrm{p}-$ aminophenol or APAP is classified as non narcotic pain reliever. Dentist generally uses it for mild to moderate dental pain. It acts as both anti - pain and antifever and has weak anti - inflammatory effect, due to poor ability to inhibit Cox in the presence of high concentration of peroxides. ${ }^{(4)}$ 
Significantly more dental pain relief can be provided by a dose of $1000 \mathrm{mg}$, at this dosage, the maximal efficacy is achieved and last up to four hours after administration. ${ }^{(5)}$

Celecoxib (celebrex) is selective cyclooxygenase -2 inhibitors Non Steroidal
Anti Inflammatory Drug. NSAIDs are effective for the management of any level of dental pain, whether mild, moderate or sever. ${ }^{(6)}$ Optimal use of these drugs resides in understanding their mechanism of action on the arachidonic acid cascades which summarized in Figure (1).



Figure (1): Arachidonic acid cascade

NSAIDs block the cyclooxygenase -1 $(\mathrm{Cox}-1)$ and cyclooxygenase -2 (Cox -2$)$. Cox -1 is responsible for the synthesis of several mediators, including prostaglandins that protect gastric mucosa. Tissue damage such as pulpitis or tissue damage resulting from surgery, will induce production of Cox -2 , which in turns lead to synthesis of prostaglandins that sensitize pain fibers and promote inflammations. ${ }^{(7)}$

Traditional NSAIDs block both Cox -1 and Cox -2 but celebrex is selectively block Cox -2 so it less damaging to gastric mucosa, and evidence support this contention. $^{(8)}$

This study aims to compare the efficacy of celebrex $400 \mathrm{mg}$ one time daily with paracetamol $1000 \mathrm{mg}$ four times daily in reducing post operative pain, facial swelling and trismus following post surgical third molar extractions.

\section{MATERIALS AND METHODS}

This study was carried out in Special Health Center of dentistry in Mosul City for period from December 2008- April 2009.

Forty five (45) patients with impacted lower third molars, age between $18-45$ years were included in this study. A complete medical history was elicited and an oral examination was performed, including radiographs for standardization of the samples, the following clinical criteria were used:

1. Ages between $18-45$ years.

2. Impacted third molars in vertical, horizontal, mesiosangular or distoangular positions (Winter's classifications).

3. Equivalent degree of surgical difficulty.

4. No use of medication that could interfere with healing process.

5. No systemic diseases. 
In addition, any pregnant or lactating women or patient who had taken analgesics or anti - inflammatory drugs during 24 hours before surgery was not included in the study. The study protocol was explained to the patients in details after which consent was obtained. Patients were allocated into two groups:

- Group I: included twenty (20) patients (eleven (11) female and nine (9) male) the patients given acetaminophen (paracetamol $500 \mathrm{mg}$ S.D.I) $1000 \mathrm{mg}$ orally four times daily for seven days post operatively.

- Group II: included twenty five (25) patients (thirteen (13) female and twelve (12) male). The patients given celecoxib ( 200 mg Alpha - Aleppo pharmaceutical Ind. Aleppo - Syria) $400 \mathrm{mg}$ orally one time daily for seven days post operatively.

During pre - operative period, all patients had clinical and radiographical evaluation and patients in group I ingested $1000 \mathrm{mg}$ of paracetamol one hour before operation, while patients in group II ingested $400 \mathrm{mg}$ of celecoxib one hour before operation. In the post operative periods, cloxam $500 \mathrm{mg}$ (Ampicillin $250 \mathrm{mg}$ + cloxacillin $250 \mathrm{mg}$, IBN HAYYAN pharm) and metronidazole 500mg (China Meheco Corporation Beijing, China) three time daily for seven days were prescribed.

Surgical extraction of third molars was carried on buccal guttering technique after adequate elevation and reflection of buccal mucoperiosteal flap under local anesthesia $(1.8 \mathrm{ml})$ of $2 \%$ lignocaine hydrochloride with 1:100.000 adrenalin (Kwang Myung Pharm. Co, Ltd, Kyunggi-do, Korea). Tooth delivery was followed by meticulous irrigation of the surgical site with physiologic saline. The three - sided mucoperiosteal flap was repositioned and suture. A single operator performed all surgical procedure. ${ }^{(3)}$

Pre - operative pain_was assessed using four - point rating scale. ${ }^{(9,10)}$ Accordingly, pain was recorded as: "0- no pain" (patient experiences no discomfort), "1mild pain" (almost unnoticeable pain), "2moderate pain" (noticeable pain, but patient can still engage in routine daily activities) and "3- sever pain" (very noticeable pain which disturbs the patients daily routine).

For each patient, the appropriate score was recorded in the questionnaire by one operator at first, second and in the $7^{\text {th }}$ post operative days.

Measurement ofswelling:

As no published method satisfied all criteria for assessing facial swelling, the measuring tape was used to measure distance from the tip of tragus of left and right ears and swelling in one - dimension only. ${ }^{(11)}$

Facial width (swelling) was measured using measuring tape. The reference points used were the tip of tragus of left and right ears, with the gonium in between. A single operator repeating the procedure three times on each patient made the measurements. The average of measurements was taken (in $\mathrm{cm}$ ) and recorded. The measurements were carried out just before the surgery and at post operative days 1,2 and 7 .

Measurement of mouth - opening ability:

A vernier - calibrated sliding caliper was used to measure maximum inter incisal mouth opening ability of the patient at the common cement of the procedure. The reference point was incisal edge of maxillary central incisor and incisal edge of mandibular central incisor at maximum opening available. The measurement were made in triplicates, the average was recorded in millimeters $(\mathrm{mm})$. The measurements were carried out just before the surgery and at post operative days 1,2 and 7 . Post operative trismus was measured as decrease in mouth opening. ${ }^{(12)}$

The data obtained from this study were analysis included descriptive and analytic methods. For descriptive way, the mean of variance were used. While One Way Analysis of Variance, Student's t test and chi - square measured for repeated measure, for interincisal opening, facial swelling and pain. The level of significant was set at $p \leq 0.05$.

\section{RESULTS}

A total of 45 patients (twenty patients (20) in group I and twenty five (25) patients in group II) were included in the analysis. The mean age of participant was $28.1 \pm 5.0$ years (range $18-45$ years). In 
group I; $(29.11 \pm 5.0)$ years and in group

II; $(27.1 \pm 4.9)$ years $($ Table 1$)$.

Table (1):Descriptive statistic of study samples of both groups.

\begin{tabular}{cccc} 
Group & Mean of age \pm SD & Minimum & Maximum \\
\hline Group I & $29.17 \pm 5.0$ & 18 & 45 \\
Group II & $27.1 \pm 4.9$ & 18 & 45 \\
\hline
\end{tabular}

SD: Standard deviation

The distribution of study samples are shown in Table (2) which shows a higher percentage of female participants. The mean age of patients in group I was $(29.17$ $\pm 5.0)$ years and in group II was $(27.1 \pm$ 4.9) years with no significant differences between them.
In relation to the sex of patient, the ratio of female to male was 1:1.1 with no significant differences in related to it which qualifies the parameters of the study between the two groups in related to age and sex.

Table (2): Distribution of study

samples according to gender

\begin{tabular}{ccc}
\hline Sex & Number & Percentage \\
Male & 21 & 46.6 \\
Female & 24 & 53.33 \\
Total & 45 & 100 \\
\hline
\end{tabular}

The radiographic analysis of the type of impaction showed that mesioangular impaction constituted a higher percen- tage $40 \%$ of impaction followed by distoangular $31.1 \%$, horizontal $20 \%$ and vertical $8.8 \%$ as showed in Table (3).

Table (3) Type of impaction

\begin{tabular}{ccc}
\hline Type & Frequency & Percentage \\
\hline Mesioangular & 18 & $40 \%$ \\
Distoangular & 14 & $31.1 \%$ \\
Horizontal & 9 & $20 \%$ \\
Vertical & 4 & $8.8 \%$ \\
Total & 45 & $100 \%$ \\
\hline
\end{tabular}

The result of facial measurement, pain and interincisal distance comparing time and patients group are shown in Table (4).

It can be observed that there is no statistical difference $(p>0.05)$ between two groups in preoperative periods in related to facial swelling, interincisal distance and pain, while there is an increase of all mean except interincisal distance between preoperative and post operative first and second day. The increase of facial swelling is greater in the group I and with lower incident of increase in the second group with a significance difference $(p \leq 0.05)$ which indicate the beneficial effect of ce- lecoxib on these measurements over the use of paracetamol.

The interincisal distance diminished in the first and second post operatively in both groups with significant differences between them $(p \leq 0.05)$ which demonstrated the beneficial effect of celecoxib on paracetamol in reduction of trismus (due to the greater reduction on interincisal distance in the first group compared with the second group).

Pain scores shows no significant differences between two groups $(p>0.05)$ in the first and second day although the pain score is higher in first group compared 
with the second group at the first day but it become higher in second group (0.28) in the second day.

By the post operative $7^{\text {th }}$ day all symp- toms had restored to the preoperative level in both groups. Neither groups demonstrated any adverse reaction, side effect or other complications.

Table (4): Mean and standard deviation (SD) of swelling, Interincisal distance , and pain according to different times and group of patient included.

\begin{tabular}{|c|c|c|c|c|c|c|}
\hline \multirow{2}{*}{ Measures } & \multirow{2}{*}{ Times } & \multicolumn{2}{|c|}{ Group I } & \multicolumn{2}{|c|}{ Group I I } & \multirow{2}{*}{$P$ value } \\
\hline & & Mean & SD & Mean & SD & \\
\hline \multirow{4}{*}{ Facial swelling $(\mathrm{cm})$} & Pre - operative & 28.5 & 3.7 & 29.1 & 4.0 & 0.17 \\
\hline & $1^{\text {st }}$ day & 32.1 & 2.5 & 30.1 & 3.2 & $0.013^{*}$ \\
\hline & $2^{\text {nd }}$ day & 34.51 & 3.4 & 30.2 & 2.5 & $0.002 *$ \\
\hline & $7^{\text {Th }}$ day & 28.5 & 3.7 & 29.1 & 4.0 & 0.17 \\
\hline \multirow{4}{*}{ Interincisal distance $(\mathrm{mm})$} & Pre - operative & 45.4 & 4.7 & 46.7 & 5.6 & 0.08 \\
\hline & $1^{\text {st }}$ day & 30.9 & 4.5 & 40.5 & 5.6 & $0.001 *$ \\
\hline & $2^{\text {nd }}$ day & 27.52 & 3.4 & 35.2 & 3.2 & $0.002 *$ \\
\hline & $7^{\text {Th }}$ day & 45.4 & 4.7 & 46.7 & 5.6 & 0.08 \\
\hline \multirow{4}{*}{ Pain } & Pre - operative & 0.25 & 0.15 & 0.31 & 0.1 & 0.09 \\
\hline & $1^{\text {st }}$ day & 0.27 & 0.2 & 0.3 & 0.11 & 0.08 \\
\hline & $2^{\text {nd }}$ day & 0.26 & 0.2 & 0.28 & 0.13 & 0.07 \\
\hline & $7^{\text {Th }}$ day & 0.0 & 0.0 & 0.0 & 0.0 & ------ \\
\hline
\end{tabular}

* Significant differences $p \leq 0.05$

\section{DISCUSSION}

Surgery of impacted third molars is one of the most frequent procedure in oral and maxillofacial su-gery. ${ }^{(13)}$ By pharmacological controlling the extent of inflammatory process. The intensity or severity of post operative complication such as swelling, trismus which is a direct sequel of the post operative swelling being able of compressing nervous structure and generate mild to sever pain. ${ }^{(14,15)}$

Celecoxib was chosen for this study because its selective Cox -2 inhibitors NSAIDs and it characterized by ${ }^{(16)}$ :

1. Less risk of GI ulceration than non selective NSAIDs.
2. Lack of effect on platelet function unlike non selective NSAIDs.

3. Generally long duration of action with once - daily administration.

The employed analgesic was paracetamol, also a proven drug of safe administration and because of the fact that it doesn't modify platelet's aggregation, coagulation time or neutrophil action. ${ }^{(17)}$ The dose used in this study was $1000 \mathrm{mg} / 4$ times daily to provide a higher analgesic and anti-inflammatory effect and it is in agreement with the study of Bjarnsson $e t$ $a l .{ }^{(18)}$

Celecoxib and paracetamol were administrated pre -operatively in this study 
and it is in agreement with the study of Hass $^{(9)}$ and Bamgbose et al. ${ }^{(11)}$ which demonstrated that when NSAIDs are administered preoperatively, absorption and distribution of the medication may occur before the initiation of tissue trauma. The ensuring synthesis of prostaglandins and the subsequent inflammatory response was prevented which may decrease the sequelae of tissue trauma especially the accompanying pain.

The preventive strategies for post operative management of pain and inflammation are based on the known ability of NSAIDs to block the arachidonic acid cascade. $^{(19)}$

According to this study, a higher percentage of impaction type demonstrated by radiograph was mesioangular impaction $40 \%$ and it is in agreement with the study of Bamgbose et al. ${ }^{(11)}$.

In related to post surgical oedema which is difficult to quantify accurately, since it requires a three - dimensional measurement with an irregular, convex surface and can manifest itself internally as well as externally, numerous researchers have tried various techniques in an effect to objectively measure of oedema. ${ }^{(20,21)}$

In the present study, a single measurement from the tip of tragus to genion to the tip of contralateral tragus was taken, it is not worthily to mention here in that the cheeck swelling followed third molars surgery is diffuse in different planes and it is very difficult to measure accurately. ${ }^{(20)}$

According to the result of this study, the administration of celecoxib $400 \mathrm{mg}$ orally one time daily enhance the control of post operative facial swelling with a significant difference $(p \leq 0.05)$ than paracetamol $1000 \mathrm{mg}$ four time daily which is in agreement with the study of Carriches et $a l .{ }^{(22)}$ and disagreement with the study of Bamgbose et al. ${ }^{(11)}$ which illustrated that dexamethasone has superior effect on diclofenac K (NSAIDS). This effect of celecoxib due to the inhibition of COX at the surgical site which limit the production of prostaglandin and prostocyclin associated with hyperalgesia and oedema compared with poor anti -inflammatory effect of paracetamol. ${ }^{(5,23)}$
According to the result of this study, celecoxib produce reduction in interincisal distance to less extent than paracetamol with significant differences between the two groups $(p \leq 0.05)$. This reduction which main determination of trismus measurement. ${ }^{(24)}$ Clarify the clinical benefit of celecoxib over paracetamol on oedema and trismus which is due in part to the conversion of phospholipids to arachidonic acid by phospholipase $A_{2}$ in neutrophil and macrophage and the resultant production of leukotrienes, prostocycline, prostaglandin and thromboxan $\mathrm{A}_{2}$ acting as a mediator of the inflammatory process. The use of NSAIDs may inhibit this process. ${ }^{(25)}$ This is in agreement with the study of Bamgbose et l. $^{(11)}$ and disagreement with the study of Bjornsson et $a l .{ }^{(18)}$

In the present study regardless of drug used, the pattern of post operative pain has been reported to increase between the post operative day 1 and 3 after which the symptoms subside gradually within one week which was recorded by other study, ${ }^{(26,27)}$ and confirm by this study. The comparison of pain intensity between group I and group II showed no significant differences between the two groups. This effect of celecoxib due to the fact that the analgesic property of NSAIDs in the oral surgery model due to suppression of a nociceptive process, presumably prostaglandins formation, rather than generalized anti - inflammatory effect ${ }^{(28)}$, while paracetamol which is used for mild to moderate dental pain has a rapid pain - killer action and at a dose of $1000 \mathrm{mg}$ maximum efficacy was achieved. ${ }^{(4)}$ This study is in agreement with the study of Bjornsson et $a l .{ }^{(18)}$ which demonstrated that there is no clinical beneficial effect of Ibuprofen 600 $\mathrm{mg}$ four times daily over traditional paracetamol regime (1000 mg four times daily).

The time course for pain, facial swelling and trismus described in the present study are in agreement with other studies ${ }^{(29,30)}$, indicating similar symptoms that reached a maximum at a days 1 or 2 post operatively and generally resolved at day $7 .^{(31)}$ 


\section{CONCLUSIONS}

The study demonstrated that celecoxib $400 \mathrm{mg}$ daily is effective as paracetamol $1000 \mathrm{mg}$ four times daily in reducing post surgical oral pain with longer duration of action and less frequency of administration with no side effect on GIT. It has also superior anti - inflammatory effect than paracetamol measured by reduction in facial swelling and trismus following third molar surgery which encourage it is use in the treatment of post surgical oral complication as a substitute of traditional use of paracetamol.

\section{REFERENCES}

1. Beeman CS. Third molar management, a case for routine removal in adolescent and young adult orthodontic patients. J Oral Maxillofac Surg. 1999; 57 (7): $824-30$.

2. Berg TI, Boe OE. Predictor evaluation of post operative morbidity after surgical removal of mandibular third molars. Acta Odontol Scand. 1994; Jun 52(3): $62-169$.

3. Filho JR, Maurette PE, Allais M, Catinho M. Clinical comparative study of the effectiveness of two dosage of dexamethasone to control post operative swelling, trismus and pain after the surgical extraction of mandibular impacted third molars. Med Oral Pathol Oral Civ Buccal. 2008; Feb 1; 13(2): 129 - 132.

4. Brunton L, Parker K, Blumenthal D, Buxton L. Goodman and Gilman's manual of pharmacology and therapeutics. McGraw Hill Medical. 2008: $445-448$.

5. Hass DA. An update on analgesics for the management of acute post operative dental pain. $J$ Canadian Dent Assoc. 2002; Sept 68(8): $476-482$.

6. Hersh EV, Moore PA, Ross GL. Over - the - counter analgesics and antipyretics: a critical assessment. Clin Ther. 2000; 22 (5): 500 - 548.

7. Dionne RA, Berthold CW. Therapeutic uses of non - steroidal anti - inflammatory drugs in dentistry. Crit Rev Oral Bio Med. 2001; 12 (4): 315 330.
8. Fitzgerald GA, Patrono C. The Coxibs, selective inhibitors of cyclooxygenase - 2. N Engl J Med. 2001; 345 (6): 433 $-442$.

9. Rodrigo MR, Rosenquist JB, Cheung LK. Paracetamol and diflunisial for pain relief following third molar surgery in Hong Kong Chinese. Int $J$ Oral maxillofac Surg. 1987; 16: 566 571.

10. Ongk O, Seymour RA. Pain measurement in humans. Surg $J R$ Call Surg Edinb Irel. 2004; 2: 15 - 27.

11. Bamgbase BO, Akinwande JA. Effect of co-administered dexamethasone and diclofenac potassium on pain, swelling and trismus following third molar surgery. Head and Face Medicine. 2005; 1 (11): 1 - 6.

12. AL - Khateeb TH, Nusuiv Y. Effect of the proteolytic enzyme servapeptase on swelling, pain and trismus after surgical extraction of mandibular third molars. Int J Oral Maxillofac Surg. 2008; 37 (3): $264-268$.

13. Skjelbred P, Lokker P. Post - operative pain and inflammatory reaction reduced by injection of corticosteroid. A controlled trail in bilateral oral surgery. Eur J Clin Pharmacol. 1982; 21 (5): $391-396$.

14. Savin J, Ogden GR. Third molar surgery - a preliminary report on aspects affecting quality of life in the early post operative period. Br J Oral Maxillofac Surg. 1997; Aug 35 (4): 246 253.

15. Ito U, Reulen HJ, Alkada J. Formation and propagation of brain oedema fluid around human brain metastases. Acta Neurochirur (Wien). 1998; 90: $35-41$.

16. Yagiela JA, Dowd FJ, Neidle EA. Pharmacology and therapeutic for dentistry. Philadelphia, Mosby. 2004: $350-352$.

17. Esen E, Taxar F, Akhan O. Determination of the anti - inflammatory effects of methyl prednisolone on the sequalae of third molars surgery. $J$ Oral Maxillofac Surg. 1999; Oct 57 (10): 1201 - 1206.

18. Bjornsson GA, Haanae HR, Skoglund LA. A randomized, double - blind crossover trail of paracetamol 1000 
mg four times daily vs ibuprofen 600 mg: effect on swelling and other postoperative events after third molar surgery. J Am Dent Assoc. 2002; May 133 (5): $611-621$.

19. Jackon DL, Moore PA, Hargreaves KM. Preoperative non steroidal anti inflammatory medication for the prevention of post operative dental pain. JADA. 1989; 119: 641 - 647.

20. Rofer EA, Roger RT. A review of preoperative corticosteroid use in dentoalveolar surgery. Oral Surg Oral Med Oral Pathol. 2000; 90: 406 415.

21. Troullors ES, Hargreaves KM, Buttler DP. Comparison of non steroidal anti - inflammatory drugs, ibuprofen and flurbiprofen with methydprednisolone and placebo for acute pain, swelling and trismus. J Oral Maxillofac Surg. 1990; 48: 945 - 952.

22. Carriches CL, Gonzalez JM. Analgesic efficacy of diclofenac versus methydprednisolone in the control of post operative pain after surgical removal of lower third molars. Med Oral Patol Oral Cir Buccal. 2005; 10: $432-439$.

23. Moore PA, Brar P, Smida ER. Preemptive rofecoxib and dexamethasone for prevention of pain and trismus following third molar surgery. Oral Surg Oral Med Oral Pathol Radiol Endod. 2005; 99: 1- 7.

24. Ustun Y, Erdoan O, Kavsli E. Comparison of the effect of two doses of methydprednisolone on pain, swel- ling, trismus after third molar surgery. Oral Surg Oral Med Oral Pathol Radiol Endod. 1996; 5: 535 - 539.

25. Hirschman JV. Some principles of systemic glucocorticoids therapy. $\mathrm{Cli}$ Exp Dermatol. 1986; 11: 27 - 46.

26. Sisk AL, Bonnington GJ. Evaluation of methydprednisolone and flurbiprofen for inhibition of the post operative inflammatory response. Oral Surg Oral Med Oral Pathol. 1985; 60: 137 $-145$.

27. Neupert EA, Philput CB, Gordon JR. The evaluation of dexamethasone for reduction of post surgical sequelae of third molar's removal. J Oral Maxillofac Surg. 1992; 50: 1177 - 1182.

28. Levine JD, Gordon NC. A randomized double - blind comparative study of Biolight therapy following surgical extraction of impacted third molars. Swed Dent J. 2007; 31 (4): $165-170$.

29. White RP, Shugars DA, Shafer DM. Recovery after third molar surgery: clinical and health - related quality of life outcomes. J Oral Maxillofac Surg. 2003; 61: 535 - 544.

30. Conrad SM, Blakey GH, Shugars DA. Patient's perception of recovery after third molar surgery. J Oral Maxillofac Surg. 1999; 57: 1288 - 1249.

31. Grossi GB, Maiorana C. Effect of submucosal injection of dexamethasone on post operative discomfort after third molars surgery: A prospective study. J Oral Maxillofac Surg. 2007; 65 (11): 2218 - 2226. 